\title{
Estado e novo arranjo para o financiamento do investimento público no Brasil *
}

\author{
Geraldo Biasoto $\mathrm{Jr}^{* *}$ \\ José Roberto Afonso ${ }^{* * *}$
}

\begin{abstract}
Resumo
A lógica do pensamento keynesiano mostra como a incerteza envolvida na imobilização de capital restringe a dinâmica da economia e a necessidade de promoção de instituições que reduzam as condições de risco. A economia brasileira tem se defrontado, há décadas, com baixo dinamismo, culminando na pior recessão de sua história. Uma das razões para essa tendência pode estar na forma de inserção estatal no investimento nacional, que não se furtou a criar instituições voltadas para mobilização de capitais e para fomento ao crescimento. Mas a montagem de um novo padrão de financiamento é decisiva para tornar mais efetiva a presença ativa do Estado no desenvolvimento. Este trabalho defende uma nova lógica institucional, tendo concessões e PPP por instrumentos, para melhorar a qualidade daquela intervenção estatal.
\end{abstract}

Palavras-chave: Política fiscal; Investimento público; Parceria; Padrão de financiamento; Infraestrutura.

\begin{abstract}
State and new investment financing arrangements: alternatives for Brazil

The logic of Keynesian thinking shows how the uncertainty involved in the immobilization of capital restricts the dynamics of the economy and the need to promote institutions that reduce risk conditions. For decades, the Brazilian economy has been facing low dynamism, culminating in the worst recession in its history. One reason for this trend could be in the form of state integration into domestic investment, which did not fail to build institutions aimed at raising capital and promoting growth. The assembly of a new pattern of funding, however, is crucial to making the state's active presence in development more effective. This paper advocates a new institutional and financial logic, with concessions and PPP instruments to improve the quality of such state intervention.
\end{abstract}

Keywords: Fiscal policy; Public investment; National budget; Deficit and Debt; Financial markets; Saving and capital investment.

JEL H3, H6, H54, E62, O16.

\section{Introdução}

Desde os anos oitenta, a economia brasileira não consegue engatar uma trajetória minimamente razoável e sustentável de crescimento. Em cada um dos

* Artigo recebido em 9 de setembro de 2016 e aprovado em 15 de outubro de 2016.

** Professor do Instituto de Economia da Unicamp (IE/Unicamp) / Coordenador do Núcleo Interno de Finanças da mesma instituição, Campinas, SP, Brasil. E-mail: biasoto@unicamp.br.

*** Pesquisador do Instituto Brasileiro de Economia da Fundação Getúlio Vargas (FGV/IBRE) / Professor do Mestrado do Instituto do Direito Púbico (IDP), São Paulo, SP, Brasil. E-mail: jose.afonso@ fgv.br. 
momentos onde isto parecia ser viável, desequilíbrios macroeconômicos apresentaram-se e resultaram até em fortes retrocessos, como o vivido recentemente.

Não há que se transferir a culpa para o resto do mundo. Embora os últimos anos da economia mundial sejam marcados pelo crescimento desigual e descontínuo, as evidencias não autorizam dizer que o ambiente internacional seja mais perverso para o desenvolvimento de países de menor tradição capitalista. Diversos exemplos evidenciam que o mercado mundial atual é mais permeável à inserção de novos players, como foi o caso da China, da Índia, da Coréia e de vários países asiáticos.

Muito mais do que o mercado ou o capitalismo mundial, as raízes das dificuldades em reorganizar uma trajetória de desenvolvimento passam por um ingrediente essencial da montagem dos padrões de crescimento, desde o final do século XIX: o padrão de inserção estatal na montagem da estrutura de financiamento ao investimento.

Neste contexto, o objetivo deste artigo é propor alternativas para redefinição do padrão de financiamento ao investimento público na economia brasileira.

Para esta análise, este trabalho divide-se em cinco blocos. O primeiro, procura descrever, em seus traços gerais, a importância das articulações e da presença efetiva do Estado no processo econômico e sua vigorosa intervenção em diversos mercados e na estruturação da economia.

O segundo bloco busca identificar as lacunas que se produziram ao longo dos anos de baixo crescimento, aonde a fragilidade do Estado resultou em dificuldades para a construção de um novo padrão de crescimento.

O terceiro bloco identifica o rompimento das relações entre o setor público e o setor privado, enfatizando a problemática da reorganização de suas interfaces num novo contexto econômico.

O quarto bloco busca extrair do pensamento keynesiano elementos para pensar o caso brasileiro. A ênfase recai na articulação entre o público e o privado e das ações de suporte à redução do risco embutido na imobilização de capital e na alavancagem de recursos financeiros para o investimento.

Por fim, o quinto bloco procura delinear novas formas de estruturação do financiamento, com participação estatal, mas num ambiente marcado pela parceria com o setor privado, com especial atenção para a remontagem do padrão de financiamento ao investimento, centrado nas instituições públicas, com a mobilização de capitais do conjunto da economia e dos fluxos de capital externo. A parte final explicita as principais conclusões e oportunidades identificadas no âmbito do trabalho. 


\section{A presença estatal}

A história da economia brasileira foi caracterizada pela forte inserção do Estado, tanto no processo produtivo quanto no campo institucional e regulatório. No início do século XX, como condutor e operador financeiro das políticas de valorização do café. Mais tarde, na função de agente estruturador do sistema tributário, do mercado de capitais e do sistema bancário, nos anos sessenta e setenta, o Estado brasileiro não foi apenas um participante do desenvolvimento, mas formulou e lançou as bases do capitalismo brasileiro.

A presença do Estado na economia brasileira é um elemento constitutivo do desenvolvimento capitalista. A dicotomia entre Estado e dinâmica econômica do setor privado é estranha à história da economia brasileira. Este ponto é fundamental, dado que as relações das várias instâncias do aparelho de Estado com o mundo privado ganham concretude dentro da própria formação dos mercados, da estrutura produtiva e das relações de classe. O movimento das estruturas públicas e das contas fiscais, somente pode ser entendido dentro deste contexto.

Pelo menos desde os anos trinta, o Estado brasileiro passou a assumir papel ativo na regulação da economia nacional. Neste período, a defesa da participação do Estado na organização da sociedade e na construção da economia nacional passou a ser uma opção das camadas empresariais. Ao mesmo tempo, uma burocracia especializada começou a regular e normatizar as principais áreas da atividade econômica, dando ao sistema uma racionalidade excepcional para uma economia marcada pelo atraso na constituição das classes e dos mercados. Os códigos que regulamentaram os serviços de utilidade pública, os planos para transporte e energia, a legislação trabalhista e de intervenção no mercado de trabalho e o planejamento setorial foram os primeiros frutos gerados por esta burocracia.

Em consequência da atuação estruturante do Estado e de sua burocracia, a economia brasileira, no início dos anos cinquenta, era dotada de grande capacidade de intervenção no sentido de materializar o projeto desenvolvimentista. Econômica e ideologicamente, o segundo Governo Vargas cuidou de desbloquear os pontos de estrangulamento que barravam a industrialização. O Estado estruturou um sistema público de financiamento ao investimento, baseado na mobilização de recursos oriundos de empréstimos compulsórios e fundos vinculados administrados pelo BNDE, criado em 1953. Em direção semelhante atuou a introdução da Instrução 70 da Sumoc, que estabeleceu uma política de importações baseada num sistema de alíquotas diferenciadas por produtos, produzindo a geração de um subsídio de alguns setores importadores para outros através dos preços da moeda externa. Por fim, com a criação da Petrobras, maior síntese do ideário nacional-desenvolvimentista, aumentou enormemente a alavancagem do Estado na atividade econômica e seu impacto na cadeia produtiva, especialmente através da política seletiva de compras ${ }^{1}$.

(1) Ver Draibe (1985, cap. 3). 
Durante o Governo Juscelino Kubistchek, a grande capacidade de articulação de capitais detida pelo Estado pode ser realmente sentida. Através dos grupos executivos ganharam maior força as relações entre o público e o privado, mediadas pela burocracia pública no desenho e na efetiva implementação das políticas setoriais. O poder de articulação do Estado ia além da demarcação dos espaços produtivos a serem ocupados para cuidar da distribuição dos espaços entre os capitais privado nacional, privado internacional e estatal. Como resultado, o boom industrial, financiado pelo capital estrangeiro e pelo investimento estatal, levou a uma enorme alteração do perfil da estrutura industrial brasileira. Note-se que somente a participação estatal na formação bruta de capital fixo saltou de 3,1\% para $8,2 \%$ do PIB, entre o início e o final do período ${ }^{2}$.

As reformas dos anos sessenta levaram o Estado a ter um potencial intervencionista jamais visto na história brasileira. A reorganização institucional, em suas várias dimensões, propiciou ao Estado alcançar um novo patamar em sua tarefa de mobilizar recursos dispersos na economia, constituir mercados e se introduzir diretamente na produção de um número expressivo de bens e serviços. A disforme institucionalidade das décadas anteriores, montada ao sabor das necessidades, assumiu características completamente distintas. Escudadas no regime de força, implantado em 1964, as autoridades econômicas levaram a cabo grande parte dos projetos para dotar a economia de um arcabouço institucional capitalista. ${ }^{3}$

Quatro grandes reformas podem ser elencadas entre os alicerces do milagre econômico dos anos setenta. A primeira delas foi a reforma tributária, que modernizou a forma de recolher recursos para a ação estatal, incrementou a carga tributária a níveis inéditos e deu condições ao Estado para promover a canalização de recursos na ausência de um sistema bancário maduro. Em um País onde o espaço fiscal se confunde com o próprio espaço econômico, a questão tributária não poderia se limitar à readequação dos tributos ${ }^{4}$. Ao contrário, dali nasceram poderosos elementos de captação de poupanças que passaram a fluir através de instituições públicas. O Fundo de Garantia por Tempo de Serviço (FGTS) foi o grande instrumento de captura de recursos, para aplicação em investimentos em saneamento

(2) O melhor exemplo do sucesso deste tipo de articulação pode ser dado pela configuração assumida pela indústria automobilística: capital internacional nas montadoras, capital nacional nas autopeças e o Estado no suprimento de insumos básicos (CSN e Petrobras) e na construção da infraestrutura básica rodoviária. Ver Fiori (1993) e Dain e Lessa (1982).

(3) A ideia de fuga para a frente se refere à reorganização das instituições e instrumentos de ação estatal, sem questionamento dos pilares de sustentação do pacto desenvolvimentista. No equacionamento da crise dos anos sessenta, o arranjo que permitiu a utilização de crédito externo é um ótimo exemplo da forma típica de encaminhamento promovida pelo Estado do pacto. Ver Fiori (1993).

(4) Para uma análise aprofundada sobre a relação entre o sistema tributário de 1966 e a dinâmica da economia, ver Oliveira (1991, cap. 3). 
básico e habitação, através do Banco Nacional de Habitação (BNH $)^{5}$. Posteriormente, em 1970, um novo encargo social, o PIS, viria a se somar à formação de poupança compulsória e à mobilização de recursos para financiar investimentos produtivos, agora através do Banco Nacional de Desenvolvimento Econômico (BNDE).

Um segundo bloco de reformas teve lugar na própria estrutura da administração pública, de modo a viabilizar uma enorme transformação da ação e da intervenção pública. Inúmeros segmentos da antiga administração direta ganharam autonomia operacional similar às empresas privadas, passando a ter a mesma racionalidade que as unidades empresariais. Visou-se implantar algo semelhante às leis de mercado na esfera pública. Através do Decreto-Lei n. 200, de 1967, a administração pública se descentralizou e pode assumir a forma jurídica de sociedade de economia mista ou empresa pública, fugindo aos entraves postos pelas regras orçamentárias e financeiras que se colocavam sobre a administração direta ${ }^{6}$.

Os principais efeitos dessas mudanças podem ser divididos em dois campos. Do ponto de vista macroeconômico, o conjunto da administração descentralizada passou a ter acesso ao crédito interno e externo. Deste modo, rompeu-se o limite dado pelo Congresso, através das leis orçamentárias, à expansão do endividamento e, por consequência, do gasto. Do ponto de vista da organização do Estado, os interesses da burocracia pública se fragmentaram setorialmente. As burocracias estatais, em estreita relação com os setores aos quais estavam vinculadas suas agências e entidades, passaram a verbalizar prioritariamente os interesses dos respectivos segmentos privados regulados ou de referência, confundindo as relações público-privadas ${ }^{7}$.

O terceiro grande segmento das reformas foi a estruturação das instituições e do sistema financeiro. As reformas neste campo se deram por quatro vias. A primeira foi a segmentação dos mercados e das instituições de crédito e captação de recursos financeiros por atribuições definidas. Desta forma, incrementou-se a oferta de crédito ao consumidor através das financeiras e a disponibilidade de recursos para a construção civil, através das associações de poupança e empréstimos, cujo mecanismo de captação era exatamente o mais popular: a caderneta de poupança. A segunda via foi a criação do mercado monetário, calcado em títulos de emissão governamental, que passou a dar substância aos negócios e à relação entre as

(5) O FGTS recolhia recursos depositados mensalmente pelos empregadores em contas individualizadas de trabalhadores que, em caso de demissão ou aquisição de imóvel próprio poderiam retirar os recursos. Desta forma, recursos que, de outra forma ficariam dispersos nas mãos dos empregadores passavam a ser canalizados para as aplicações do antigo BNH.

(6) Note-se que a Constituição de 1969 reforçou a autonomização da administração indireta ao estipular a presença no Orçamento apenas das entidades recebedoras de transferências e subvenções orçamentárias, mesmo assim, na forma de dotações globais. Ver Mussi e Silva (1992).

(7) Este processo foi descrito como feudalização do setor público. Ver Martins (1985). 
instituições no mercado em formação. A terceira via foi a criação da Obrigação Reajustável do Tesouro Nacional (ORTN), justamente por sua característica de oferecer um papel com correção monetária e balizamento às aplicações de maior prazo. A quarta via foi a regulamentação da captação de empréstimos em moeda estrangeira, junto a fontes externas, realizada através da Lei n. 4131, de 1964. Notese, também que a criação do Banco Central do Brasil (BCB), que substituiu a Superintendência da Moeda e do Crédito (Sumoc), foi decisiva para alavancar a capacidade financeira do Estado.

Por fim, a quarta das grandes reformas ocorridas em meados dos anos sessenta refere-se ao mercado de câmbio. A política cambial inaugurada com a criação do Banco Central do Brasil manteve o monopólio cambial vivido nas décadas anteriores. As Autoridades Monetárias seguiram sendo canal obrigatório para as transações entre a moeda nacional e as moedas externas, tanto na esfera comercial quanto na financeira. A introdução da política de minidesvalorizações deu aos agentes econômicos conhecimento da regra cambial, que poderia ser sintetizada na desvalorização frente ao dólar pelo diferencial entre a inflação brasileira e a americana.

\section{0 rompimento das relações público-privadas}

A intervenção estatal, a partir dos anos oitenta, foi a antítese da realidade do período anterior. Ao invés de ditar o processo de desenvolvimento e dar os parâmetros e diretrizes para a inserção privada no desenvolvimento, o Estado utilizou seus instrumentos de intervenção para a execução do ajustamento à nova realidade. $\mathrm{O}$ antes inquestionável aparato intervencionista passa a ser um entrave. Embora as estruturas institucionais seguissem existindo, já não geravam os efeitos dinâmicos na economia.

A análise da execução da política fiscal nos últimos trinta anos mostra alguns traços permanentes, conquanto tenham sido vividos momentos de caráter expansionista e restritivo. Estes traços permanentes podem ser sintetizados em dois aspectos:

a) desmoronou a capacidade de iniciativa governamental, típica do padrão histórico de desenvolvimento do tipo state led, onde instrumentos parafiscais acabavam produzindo os recursos a serem mobilizados para cumprir as tarefas mais imediatas da agenda desenvolvimentista; e

b) a racionalidade da estruturação do Estado, montada nos anos sessenta e setenta, esgotou-se em suas várias dimensões, especialmente no que tange à capacidade de mobilização de poupanças e de recursos para o investimento. 
A condução da política físcal foi marcada pela absoluta supremacia da administração de caixa. Nela, a racionalidade da receita pública e a execução de despesa com planejamento e objetivos definidos foram, sempre, determinantes secundários frente ao compromisso primordial com o superávit primário.

É fundamental notar que a questão fiscal, embora central em toda a discussão sobre a crise brasileira, deu lugar a inúmeros movimentos contraditórios por parte da política econômica. O processo de ajustamento conduziu os instrumentos de intervenção estatal à esterilidade, do ponto de vista de sua capacidade de impulsionar a economia. As diversas ferramentas que estruturaram a economia brasileira contemporânea esgotaram sua capacidade de ação, aprofundando a desestruturação do padrão de intervenção estatal ${ }^{8}$.

Na ausência de uma perspectiva que levasse em conta as relações públicoprivadas transformadas pelo desenvolvimento, a tônica geral da presença do Estado foi seu confinamento ao aspecto orçamentário, sempre com o direcionamento ao equilíbrio e ao controle dos gastos. As resistências às mudanças, no sentido da manutenção de padrões de gasto ampliado, foram fortes. Mas, mesmo estas, já não podem ser caracterizadas como defesa de uma forma de inserção estatal. Podem ser melhor caracterizadas como forças do tipo parasitárias, no melhor estilo das teorias de rent seeking.

Em verdade, uma análise da política fiscal das últimas três décadas indica um significativo processo de falsificação dos temas relevantes. Talvez o melhor exemplo seja a decomposição e o descontrole das fontes de financiamento do Estado. A dívida pública deixou de ser o lastro usado para formação do mercado financeiro, e a última barreira contra a fuga para moedas estrangeiras, para ser tomada como indicador dos desequilíbrios passados nas contas do setor público. Note-se que a própria taxa de juros, preço macroeconômico fundamental na condução da política econômica, passa a ser tratada apenas como o prêmio de risco aos agentes que carregam a dívida mobiliária.

A questão do déficit público foi o mais claro exemplo da dificuldade em lidar com as contas do Estado brasileiro. Os anos setenta simplesmente não tomaram conhecimento do tema, a não ser no final do período, onde o recrudescimento do processo inflacionário deu lugar ao início de seu questionamento. Ao contrário, nos anos oitenta, o esforço, dirigido a princípio pela pressão exercida pelo Fundo Monetário Internacional, em medir e controlar o déficit, foi ponto essencial nas agendas de todas as diversas equipes econômicas ${ }^{9}$.

(8) Ver Biasoto (2006).

(9) Ver Jaloretto (2009). 
Nesta perspectiva, é crucial ressaltar o caráter singular da interpenetração entre os domínios cambial, creditício e fiscal, todos inseridos na estruturação das Autoridades Monetárias. Estas últimas, detentoras, a um só tempo, do monopólio do câmbio, de uma ampla parcela da determinação do crédito global da economia, da gestão da dívida mobiliária e dos passivos em moeda estrangeira, além de uma expressiva parcela das políticas fiscais. De outro lado, a construção do conceito de déficit, inspirado pelo Fundo Monetário Internacional, implicou uma visão reconcentrada do aparato estatal, diametralmente oposta à descentralização movida pela reforma administrativa dos anos sessenta. Todo o processo de extroversão ocorrido com o aparelho estatal reverteu-se numa centralização do conjunto de entidades e instrumentos em torno do Tesouro Nacional, o que quase eliminou a capacidade propulsora de iniciativas estatais.

Essa centralização, no entanto, se deu apenas do ponto de vista da capacidade financeira de ação destas entidades. A lógica do processo de descentralização, ao embutir a ideia de intervenção nos mercados e setores específicos, levou à problematização de um dos traços característicos do Estado no capitalismo, qual seja, a dificuldade em delimitar as relações público-privadas. No caso brasileiro, a natureza da ação estatal, que se encarregou de estruturar o próprio capitalismo, colocou condições ainda mais complexas. As reformas realizadas nos anos sessenta estabeleceram uma ótica privada para atuação das entidades descentralizadas e das empresas estatais, o que, no entanto, se transformou no fracionamento do setor público em interesses de segmentos específicos, na maior parte das vezes atuando apenas como caixa de ressonância dos interesses privados relacionados ao setor.

A emergência do déficit público como tema básico das políticas econômicas de estabilização reflete-se na revisão do formato macroeconômico da intervenção estatal. Muito mais que a definição de uma variável da política macroeconômica, a questão do déficit revela uma nova postura sobre a participação estatal na economia. A controvérsia sobre as contas públicas, que ganhou grande evidência ao final de 2014, mostrou as enormes dificuldades técnicas para discutir o tema em seu caráter primordial de capacidade de comando sobre a máquina pública. A descrença na sua metodologia e nas estatísticas, juntamente com o temor quanto à manipulação dos seus números, sobrepôs-se ao caráter macroeconômico.

O papel cumprido pelo déficit parece ter sido muito distinto do que lhe é atribuído pelas teses conservadoras. $\mathrm{O}$ déficit passou a ser percebido pelo conjunto dos agentes econômicos como um índice do processo de desagregação do Estado enquanto condutor do desenvolvimento. O esgotamento do padrão de financiamento estatal acabou produzindo uma realidade que condicionou a própria escolha da variável mais utilizada para medir o déficit: o conceito de Necessidades de Financiamento do Setor Público Não Financeiro (NFSP), cujo principal atributo é o 
de medir o desequilíbrio das contas públicas através das fontes de crédito. Este passou a ser o conceito relevante para a crise financeira do Estado.

A análise dos resultados das contas públicas, sintetizado pelos números do déficit público e do superávit primário, não indica uma desestruturação que possa explicar todo o peso da crise do Estado na crise brasileira. As demandas postas para o Estado multiplicaram-se com a emergência de políticas sociais para os menos favorecidos, com a obrigação de atendimento às classes médias urbanas e com a crescente debilidade do aparelho produtivo nacional. Na verdade, embora grande parte das demandas não seja atendida, em decorrência do controle do fluxo de caixa, a tensão sobre as contas públicas é permanente.

Os elementos acima expostos indicam que a economia brasileira viveu um processo de deterioração fiscal. Mas a mera afirmação disto é como reduzir o problema apenas à sua expressão mais visível. Em verdade, a economia brasileira vive uma crise de grandes proporções no que toca a seu padrão de intervenção estatal. Para qualquer economia capitalista, isto já seria um grande obstáculo ao crescimento e ao desenvolvimento de sua estrutura produtiva e social. Para uma economia que teve no Estado sua mola propulsora, dentro de um padrão do tipo state-led, esta é uma questão central na paralisia de sua dinâmica.

Em economias com a inserção estatal do tipo da que caracteriza a brasileira, o rompimento do padrão de intervenção estatal não significa apenas a paralisia da ação pública. Ao contrário, a importância das condições de regulação de mercados, os formatos institucionais, o sistema tributário e o gasto público são de tão cruciais para as decisões privadas que estas enfrentam paralisação da mesma magnitude que a estatal. Vale dizer, a crise do Estado e de sua capacidade de intervenção é refletida na paralisia das decisões privadas.

Necessário enfatizar que este processo abarca o conjunto da ação estatal, seja no que concerne ao gasto público, seja no campo da regulação. Mas dois aspectos foram atingidos de maneira mais intensa. O primeiro é o investimento público, comprimido entre as dificuldades na redução das despesas de pessoal e custeio da máquina pública e pela necessidade de obtenção de resultados superavitários. $\mathrm{O}$ segundo é o financiamento ao investimento, tanto o público como o privado, onde as estruturas herdadas do final do século passado não foram objeto da modernização requerida, especialmente na adaptação aos novos formatos de ativos e posições patrimoniais próprios do capitalismo atual e da abertura aos fluxos financeiros externos.

\section{Elementos da incerteza e da institucionalidade na intervenção estatal}

A obra do economista britânico John Maynard Keynes talvez tenha como marca mais profunda a vinculação entre a economia, no seu movimento real, e o 
cumprimento de suas tarefas em propiciar à sociedade as melhores condições de emprego, renda e equidade. Por isso, introduziu o Estado, como agente mediador e articulador dos móveis privados, seja de empresas, seja de indivíduos, no processo econômico.

Em Keynes, o Estado ganhou lugar na dinâmica da economia, não como agente centralizador de decisões, mas como elemento ativo de um processo de múltiplos agentes. Mas ganhar lugar nunca significou para Keynes uma restrição ao papel dos agentes privados, como comprova o seguinte trecho da Teoria Geral ${ }^{10}$ :

As implicações da teoria exposta nas páginas precedentes são, a outros respeitos, razoavelmente conservadoras. Embora essa teoria indique ser de importância vital o estabelecimento de certos controles sobre atividades que hoje são confiadas, em sua maioria, à iniciativa privada, há muitas outras áreas que permanecem sem interferência (Keynes, 1996, p. 345).

Se a presença privada não é negada por Keynes, não é menos verdade que ele teoriza sobre os seus limites, no que toca à sua capacidade de dar consequência a toda a necessidade de investimentos que produziriam uma situação de proximidade ao pleno emprego. Entendemos aqui o uso do termo socialização no sentido da intervenção estatal promovendo as decisões da sociedade e produzindo uma situação de hibridismo que objetiva reduzir as incertezas da imobilização da riqueza que o investimento necessariamente implica. Senão, veja-se a continuação da reflexão acima transcrita:

... parece improvável que a influência da política bancária sobre a taxa de juros seja suficiente por si mesma para determinar um volume de investimento ótimo. Eu entendo, portanto, que uma socialização algo ampla dos investimentos será o único meio de assegurar uma situação aproximada de pleno emprego, embora isso não implique a necessidade de excluir ajustes e fórmulas de toda a espécie que permitam ao Estado cooperar com a iniciativa privada. Mas, fora disso, não se vê nenhuma razão evidente que justifique um socialismo do Estado abrangendo a maior parte da vida econômica da nação (Keynes, 1996, p. 345).

E vale frisar que Keynes manteve uma posição muito pouco ideologizada sobre a predominância pública ou privada na economia. O foco primordial era realmente a capacidade das políticas em manter a economia em nível próximo ao pleno emprego, sendo a intervenção estatal apenas uma variável instrumental.

Logicamente, faz parte do arcabouço teórico keynesiano, em termos mais gerais o temor de que a exacerbação da incerteza frente à mobilização de capitais

(10) Para uma discussão mais aprofundada deste ponto ver o tópico 1.2.4 (superioridade do investimento público) em: Afonso (2010, cap. 4). 
cada vez mais expressivos, como tendência, fosse um indutor de uma lógica de socialização do investimento. Senão, veja-se o trecho abaixo:

Não é a propriedade dos meios de produção que convém ao Estado assumir. Se o Estado for capaz de determinar o montante agregado dos recursos destinados a aumentar esses meios e a taxa básica de remuneração aos seus detentores, terá realizado o que lhe compete. Ademais, as medidas necessárias de socialização podem ser introduzidas gradualmente sem afetar as tradições generalizadas da sociedade (Keynes, 1996, p. 345).

É clara a existência de um espaço para a ação estatal, na visão de Keynes, e não era apenas aquele definido pela necessidade de debelar a crise ou a retração cíclica. Ao contrário, há elementos na dinâmica capitalista, notadamente a exacerbação da incerteza, intrínseca ao sistema, na imobilização de capital. A importância do investimento governamental cresceu nos anos quarenta, já mais distante do rescaldo da sobreacumulação de capital do final dos anos vinte. A prioridade ao investimento fica muito clara na carta que escreveu a Josiah Wedgwood, em julho de 1943:

Surge então a pergunta, por que hei de preferir uma escala pesada de investimento para aumentar o consumo. Minha principal razão para isso é não crer que tenhamos ainda atingido nada parecido com o ponto de saturação de capital. Seria interessante para o padrão de vida a longo prazo que aumentássemos materialmente nosso capital. Depois de vinte anos de investimento em larga escala eu esperaria ter de mudar de ideia. Até nesse meio tempo a questão é de grau. Mas por certo nos primeiros dez anos após a guerra - eu esperaria mais dez depois disso - não seria do interesse da comunidade incentivar maiores gastos com comida e bebida às expensas de gastos com a habitação. Pois, de um modo geral, este seria o resultado (Keynes, 1980, p. 102).

A dinâmica capitalista é uma sequência de movimentos onde as estruturas e instituições nascem, florescem e entram em colapso, até que sejam recuperadas ou reorganizadas pelo Estado. Note-se que aqui entende-se o Estado como um catalisador dos distintos interesses, cuja eficiência está em função da capacidade de negociação e articulação com os distintos atores econômicos e sociais. Este ponto foi desenvolvido por autores como Hyman Minsky, como atestado pelo seguinte trecho de um artigo já ao final de vida:

The New Deal restructuring of capitalism created institutions that contained uncertainty. The evolution of the economy has decreased the effectiveness of the New Deal reforms, and money manager capitalism has radically increased uncertainty. The creation of new economic institutions that constrain the impact of uncertainty is necessary (Minsky, 1996, p. 359). 
Instituições são cada vez mais importantes no capitalismo contemporâneo, especialmente porque a grande questão da mobilização de recursos financeiros é o risco de capital envolvido. No mundo dos ativos, tanto os aplicadores quanto os tomadores têm que colocar imensa cautela na gestão de risco de suas posições ativas e passivas. Uma institucionalidade de estruturas mais sólidas é de grande valia para a mitigação dos riscos envolvidos

E se já era verdade na época em que Keynes escreveu, agora a necessidade de uma funcionalidade entre a poupança em seu sentido macroeconômico, e sua canalização em ativos financeiros é absoluta. Numa economia capitalista com sistema financeiro e mercado de capitais organizados, todos os elementos de risco são permanentemente avaliados. Não que isto impeça as crises, dado que são próprias dos desdobramentos do ciclo e dos circuitos financeiros nele inscritos, mas, certamente, suas deficiências impedirão que o sistema consiga alavancar os recursos abortando os movimentos de crescimento. A necessidade de formas institucionais e entes que compatibilizem os prazos de ativos é muito bem apontada por Paula (2013):

\begin{abstract}
Embora a poupança seja criada simultaneamente com o investimento, isto não significa que ela se torna imediatamente e da forma apropriada disponível para consolidar as dívidas dos investidores. Ela pode, por exemplo, ser usada para comprar ativos de curto prazo, se a preferência pela liquidez dos agentes estiver aguçada e/ ou não houver instrumentos financeiros adequados para canalizar a poupança para ativos financeiros de longo prazo (p. 379).
\end{abstract}

Em uma economia como a brasileira, caracterizada por um sistema financeiro privado demasiado avesso aos riscos no longo prazo e pela forte presença do Estado na institucionalidade do padrão de financiamento da economia, as questões acima colocadas apresentam-se de maneira ainda mais intensa. É lógico que fundos públicos, BNDES e as outras instituições oficiais de crédito, seguirão tendo importância decisiva no financiamento do investimento. Não há dúvidas de que a mobilização de poupanças sempre terá uma arbitragem estatal decisiva para viabilização das pactuações de mercado. Mas não é menos verdade que a intervenção estatal num novo patamar de desenvolvimento capitalista exige novos instrumentos e reordenamentos institucionais relevantes.

Por décadas, especialmente no investimento em infraestrutura, a debilidade da institucionalidade do financiamento foi resolvida com a ação direta do Estado. Mas, na derrocada de sua capacidade financeira, a entrega de tarefas ao setor privado foi realizada sem que um novo padrão de relações financeiras e institucionais fosse construído. A transferência ao setor privado não poderia deixar de mostrar seus limites. O problema de alavancagem de recursos apenas mudou do Estado para o parceiro privado. Na sequência, alguns elementos para a construção de um novo padrão de financiamento para o investimento são colocados, com ênfase numa mudança do papel do Estado que, de forma alguma, reduz sua importância. 


\section{Padrões de intervenção estatal: elementos para sua reorganização}

A virada do século tem questionado de maneira profunda o estilo de intervenção que caracterizou o Estado brasileiro. A questão vai muito além da capacidade de realização de investimentos públicos pela ação governamental. Estão em discussão a capacidade de mobilização de poupanças, a condição de arbitragem dos conflitos pelo Estado e as estratégias de desenvolvimento. Vale lembrar que todo processo expansivo carrega elementos de desequilíbrio nos campos real, financeiro e cambial. Certamente, o Estado é, agora, muito mais relevante na gestão dos conflitos do que há 40 anos atrás.

Os limites à capacidade de ação do Estado, como agente articulador do processo de desenvolvimento, são crescentes à medida que a organização econômica ganha em complexidade e os canais financeiros ampliam sua profundidade e comunicação com as finanças globais, tanto no que toca ao sistema bancário, quanto no que tange à lógica financeira das empresas produtivas.

O desafio para o Estado recuperar protagonismo é muito maior neste contexto. Isto envolve instrumentos e instituições muito mais sofisticadas do que as utilizadas no passado. Mas recuperar o protagonismo significa mais do que ter poder de fogo para controlar o jogo especulativo. Na verdade, implica coordenar os interesses e agrupar um conjunto expressivo de atores econômicos, políticos e sociais em torno de conjunto de projetos específicos que tenha coerência e sustentabilidade macroeconômica. Em certo sentido, envolve expandir fronteiras do mercado conhecido (Mazzucato, 2011).

Logicamente, a tarefa de reordenar o padrão de intervenção estatal abarca múltiplas questões e tarefas e exige uma abordagem e discussão muito mais ampla do que a realizada neste texto. Aqui, a proposta é tratar ao menos de tarefas essenciais para a reorganização de um padrão de intervenção estatal no financiamento do investimento de interesse imediato da economia brasileira. ${ }^{11}$

\subsection{As parcerias no investimento}

O Estado sempre será elemento decisivo das decisões de investimento na economia brasileira: seja por sua capacidade de mobilização de recursos, seja por seu papel determinante na organização dos mercados e nas questões regulatórias, a presença estatal organiza o campo das decisões privadas. Mas esta constatação não implica que o país esteja condenado a investimentos ineficientes ou à prevalência do superávit primário contra a alocação de recursos para os investimentos públicos.

(11) Conceitos e propostas desenvolvidos nesta parte do texto tiveram a parceria de José Roberto Afonso. Em especial no artigo: Biasoto e Afonso (2013). 
O primeiro passo nesta direção seria usar um ensinamento de Keynes sobre os orçamentos públicos: separar em duas partes o orçamento público traria a possibilidade de gerar dinâmicas específicas para, de um lado, agrupar as despesas correntes, como as de pessoal e demais custeios e, de outro, as despesas de capital, incluindo os investimentos ${ }^{12}$. Além disso, uma abordagem de política fiscal que contemple o conceito de demanda efetiva não pode deixar de considerar a diferença entre o custeio e o capital em suas inserções dinâmicas e no desenrolar do ciclo.

O investimento público contém diversos tipos de intervenção, desde obras como construção de escolas e unidades básicas de saúde a grandes ações, como transposições de cursos hídricos ou ferrovias. Uma série destes investimentos tem um rito normal e absolutamente compatível com a execução orçamentária e procedimentos usuais da esfera pública. As grandes intervenções padecem, no entanto, de enorme insuficiência na observância dos ritos orçamentário e de compras da administração direta. O grande avanço, em termos de planejamento e execução, deve focar as intervenções públicas de grande magnitude. Um novo modo de articulação deveria focalizar os projetos fundamentais para o desenvolvimento do país. Estes projetos seriam realizados em parceria financeira e técnica com o setor privado. Distintos formatos jurídicos são aplicáveis, seja no formato de concessão pura, seja no modelo de parcerias público-privadas (PPP).

Nos dois casos, concessões ou PPP, os projetos poderiam ficar sob a responsabilidade de sociedades de propósito específico, tanto com poder decisório público quanto privado. A possibilidade do comando público é um aspecto essencial, porque amplia o leque de possiblidades de parcerias e gera a condição de assunção de riscos que, muitas vezes, o setor privado não tem condição de enfrentar.

A possibilidade de novos arranjos societários, onde a propriedade pública de um projeto é organizada sob um padrão privado, é decisiva. Em ações de grande vulto, a questão da governança na condução do projeto é crucial. Segregar os grandes projetos da lógica orçamentária geral, sempre refém do curto prazo e das pressões de caixa, garante que as expectativas dos mercados se organizem com vistas a seu sucesso, em contraposição à descrença das últimas décadas. Vale frisar, a empresa majoritariamente controlada pelo Estado deve ser dotada de governança e gestão características do mundo corporativo privado. Além disso, é necessário que sejam colocados limites muito claros à ingerência de elementos estranhos à realização do projeto com a melhor eficiência técnica ${ }^{13}$.

(12) Keynes (1980). Para uma discussão mais aprofundada, ver Afonso (2010).

(13) Nem é preciso dizer que os escândalos políticos e policiais brasileiros recentes depõe contra esse fator, o que só reforça a necessidade de mudanças institucionais, mas que já estão em curso - caso da chamada lei de responsabilidade das estatais. 
A possibilidade de uma posição majoritária do Estado em sociedade de propósito específico tem um objetivo muito bem definido e nada tem a ver com a intenção de um comando do Estado em sua fase de execução. Muito pelo contrário, a inserção estatal, como decisão da sociedade, deve ser preponderante na fase de definição do investimento e dos benefícios que o projeto produzirá.

A possibilidade de o setor privado ser minoritário respeita ao duplo caráter da relação entre o mercado e o Estado. Por riscos regulatórios não passíveis de mensuração, diversos empreendimentos não podem ser alocados a empreendedores privados. Tanto pelos prazos envolvidos na obtenção de licenças, quanto pelos riscos incorridos no período construtivo, projetos cruciais para o país simplesmente ficam inviabilizados. Uma forma derivada desta mesma questão, é o Estado incorrer em custos altíssimos pela transferência de riscos de difícil aferição, inerentes ao projeto, ao parceiro privado ${ }^{14}$.

A proposição aqui colocada é trocar a abordagem sobre os projetos da velha diretiva de uma ação pública a fundo perdido e sem avaliação de seus impactos por uma identificação das taxas internas de retorno envolvidas em cada projeto. Logicamente, há projetos economicamente viáveis, segundo padrões de mercado, mas também há projetos com taxa interna de retorno inferior, mas dotados de relevância para a economia e, assim, produtores de impactos econômicos indiretos positivos. Esses projetos deveriam ter o novo desenho como base, tanto na formulação como na execução, desenvolvendo ações gerencialmente eficientes e financiáveis por instrumentos e instituições de mercado ao lado de recursos mobilizados pelo Estado.

Há diversos tipos de intervenções ou empreendimentos a serem realizados. Em cada caso, as taxas de retorno são distintas. O mesmo se coloca para os riscos envolvidos nos investimentos, que são diferenciados, assim como os riscos de construção e operação.

Embora a complexidade das operações para a aplicação de recursos em PPP e concessões seja crescente, dado que a sofisticação dos projetos e estruturas de mobilização de recursos são singulares e envolvem diferentes atores, tentaremos focalizar três problemas sempre presentes nessa temática.

O primeiro deles é a taxa interna de retorno (TIR). Deste ponto de vista, os projetos relevantes para o país poderiam ser caracterizados como de três ordens:

$\checkmark$ Projetos autossustentáveis, são aqueles que possuem geração interna de recursos ao próprio projeto, o que garante rentabilidade compatível com a

(14) Note-se que os riscos de difícil precificação tendem a ser sobre avaliados, o que torna diversos projetos de realização inviável por agentes privados. Este um dos maiores e mais apropriados sentidos de "socialização do investimento" numa acepção keynesiana do termo. 
aplicação de capital em condições de mercado. São projetos em que a geração de receitas frente aos compromissos de investimento e custos de operação proporcionam uma Taxa Interna de Retorno (TIR) compatível com o retorno esperado de qualquer empreendimento.

$\checkmark$ Projetos com elevado grau de incerteza acerca da sua condição de auto sustentabilidade. São projetos que têm possibilidades de produzir uma taxa de retorno adequada às perspectivas do mercado, mas cujas incertezas, em termos de receitas, custo do investimento ou despesas de operação, produzem dúvidas na ótica dos empreendedores e dificuldades na construção de adequadas estruturas de financiamento e seguro.

$\checkmark$ Projetos com rentabilidade positiva, mas com expressivas dificuldades para alcançar uma taxa de retorno compatível com as perspectivas de investimentos privados. Nestes casos, a TIR é consistentemente inferior à taxa de mercado, ficando a realização do empreendimento na dependência de compensações provenientes do Estado. Estas seriam legitimadas pelas economias externas produzidas pelos projetos, em particular aqueles de grande interesse para a coletividade.

São distintas as formas e necessidades de intervenção para cada um dos tipos de projeto acima descritos. Os projetos "autossustentáveis" precisam apenas de adequados mecanismos de articulação para sua viabilização. Já os projetos com elevado grau de incerteza dependem de articulação e credibilidade política para que os capitais privados se sintam motivados a enfrentar o risco. Por seu turno, os projetos com rentabilidade positiva, mas prejudicados por TIR baixa, merecem aportes efetivos de recursos públicos, no sentido de que sustentam e potencializam políticas de desenvolvimento econômico.

Pela ótica do orçamento público, a estruturação de operações públicoprivadas representa a potencialização das disponibilidades de recursos para o investimento, prejudicadas há décadas, em decorrência dos compromissos com o superávit primário, o custeio da máquina pública e os gastos sociais. O orçamento federal não tem conseguido ampliar os recursos para investimento. Chegar a $1 \%$ do PIB foi uma tarefa que envolveu grande dificuldade e seguramente não se sustentará nos próximos anos.

Uma breve estimativa da ampliação do investimento indica um potencial expressivo. Duas hipóteses de trabalho:

$\checkmark$ considerando a utilização de uma parcela de $0,4 \%$ do PIB, segregados dos atuais investimentos, para financiamento dos projetos aqui enfocados; e

$\checkmark$ que os recursos públicos envolvidos nas parcerias fossem, em média, $25 \%$ do financiamento global dos projetos, incluída a parcela a fundo perdido 
para equalizar taxas de retorno esperado mais baixas que as aceitáveis pelo mercado.

A parcela dos investimentos alocada aos novos projetos, nesta projeção muito preliminar, pode chegar a montante de 1,6\% do PIB. Somando esta parcela aos $0,6 \%$ do PIB, que seriam preservados sistemática tradicional da máquina pública, o orçamento fiscal, somente da União, "comandaria" investimentos de cerca de 2,2\% do PIB.

\subsection{Financiamento do investimento}

Um aspecto decisivo na construção de parcerias com o setor privado é a estrutura de financiamento dos projetos. A trajetória de expansão das PPP foi seguida por uma ampliação das fontes de recursos, mas isto se deu primordialmente através dos agentes públicos de crédito, notadamente Banco Nacional de Desenvolvimento Econômico e Social (BNDES) e Caixa Econômica Federal (CEF). No caso desta última, especialmente com recursos do FI-FGTS (Fundo de Investimento do FGTS), cuja gestão é exercida pela própria CEF. ${ }^{15}$

$\mathrm{Na}$ verdade, os problemas da estrutura de financiamento dos projetos se desdobram em duas questões. A primeira é a composição de financiamento de um projeto propriamente dita. Mesmo que existam recursos para o financiamento em geral, o projeto, quando focado isoladamente, não possui uma gama de alternativas de agentes financiadores que seja suficiente para diluir os riscos para cada um destes agentes. Ou seja, os poucos agentes que ofertam crédito têm a sua participação limitada nos projetos por uma questão de concentração de risco. Ocasionalmente, as empresas que participam das sociedades de propósito específico (SPE), constituídas para gerir as PPP, conseguem mobilizar outras fontes de recursos, que, pela própria natureza, são bem mais caros e oferecem incertezas muito expressivas no tocante ao acesso aos mesmos.

Um segundo tema relevante se faz presente, a oferta de crédito existente, em muitos casos, revela-se inacessível para parcela expressiva das empresas que participam dos processos licitatórios, visando a estruturação de PPP ou voltados a concessões públicas. Quando a empresa não pertence aos grandes grupos ligados a atividades de infraestrutura, as condições de acesso tornam-se muito mais limitadas. Aumentam o tempo de negociação do crédito e os custos colaterais, o que resulta em dificuldades, por vezes intransponíveis, na estruturação do financiamento do empreendimento. Portanto, debilidades no acesso ao crédito de longo prazo

(15) Criado pela Lei n. 11.491, de 20 de junho de 2007. Para uma discussão profunda sobre o tema da institucionalidade do financiamento via títulos de dívida corporativa, ver Torres e Macahyba (2012). 
prejudicam as condições concorrenciais e limitam a participação de empresas menores, embora tecnicamente habilitadas.

A avaliação de diversos processos de parceria conduzidos pelo Estado brasileiro poderia ensejar a crítica de que, muitas vezes, ao invés de uma parceria, houve uma simples transferência de um problema a terceiros. Empurrar um problema de Estado para um agente privado é um equívoco de grande magnitude. Ao contrário, dentro de uma estratégia de parcerias com o setor privado, o Estado tem que reforçar suas tarefas nobres, especialmente a de reorganizar as condições de mobilização de poupanças e o acesso dos investidores a recursos mobilizados pela via dos fundos financeiros.

A formação de um fundo público para participar na estrutura de financiamento dos empreendimentos prioritários seria uma forma de alavancar a realização de projetos. Sua função seria reduzir as dificuldades de estruturação financeira das operações e ampliar o leque de empreendedores com capacidade para organizar o funding de suas propostas na participação nos investimentos.

A criação de um Fundo de Investimento em Parcerias, gerido pelo Estado, com o objetivo de participar do capital na formação das Sociedades de Propósito Específico (SPE), constituídas para implementação das PPP e concessões públicas, poderia ser uma grande possibilidade de melhoria das condições de financiamento. Como visualmente identificado por meio do Figura 1, esta participação seria previamente indicada, em valor monetário, em cada edital de licitação. Desta forma, os licitantes teriam, de antemão, o volume do aporte de capital pelo FIP. Alternativamente, o FIP poderia participar, pela compra de debentures, no sentido de colaborar na composição dos recursos durante o período de construção, sempre o mais crítico na mobilização de recursos.

FIP: Fundos e Aplicações

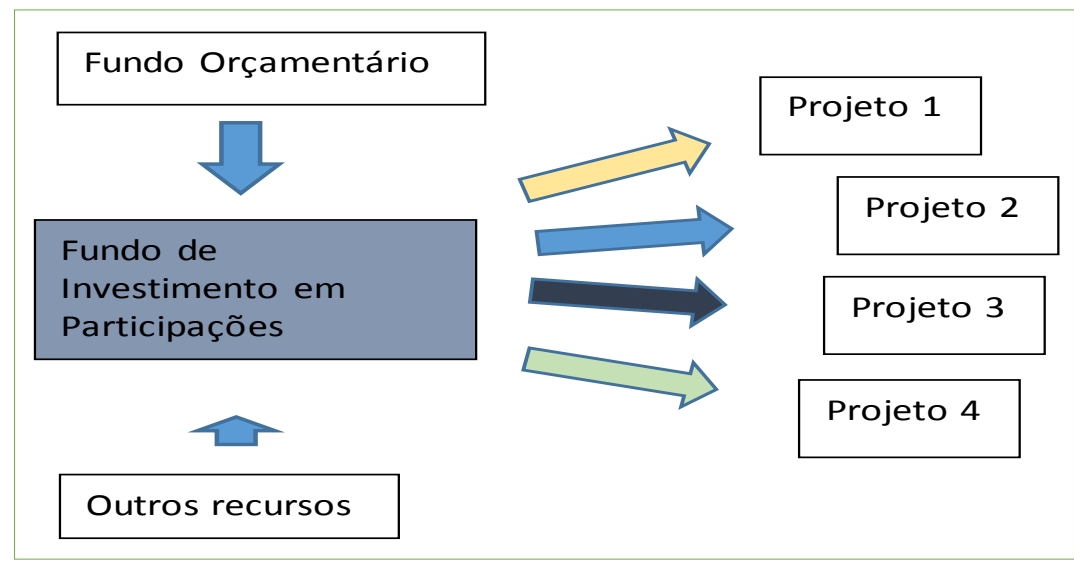

Fonte: Elaboração própria. 
Em cada projeto, a estrutura de financiamento pode se comportar de maneira diferenciada, tanto pelas especificidades do setor como pelas condições e perspectivas dos controladores. O mix de recursos, em geral, contém os elementos identificados pela Figura 2: recursos tomados ao sistema bancário nacional, papéis colocados junto ao mercado e capital próprio dos controladores da SPE. O fato novo é a entrada do FIP na composição do funding do investimento, participando com recursos próprios. Em cada um dos projetos, a estrutura se diferencia em seu perfil, fato que responde às especificidades do projeto, características dos agentes controladores e mesmo à conjuntura do mercado financeiro quando da montagem da estruturação financeira do projeto.

Figura 2

Estrutura de financiamento de projeto

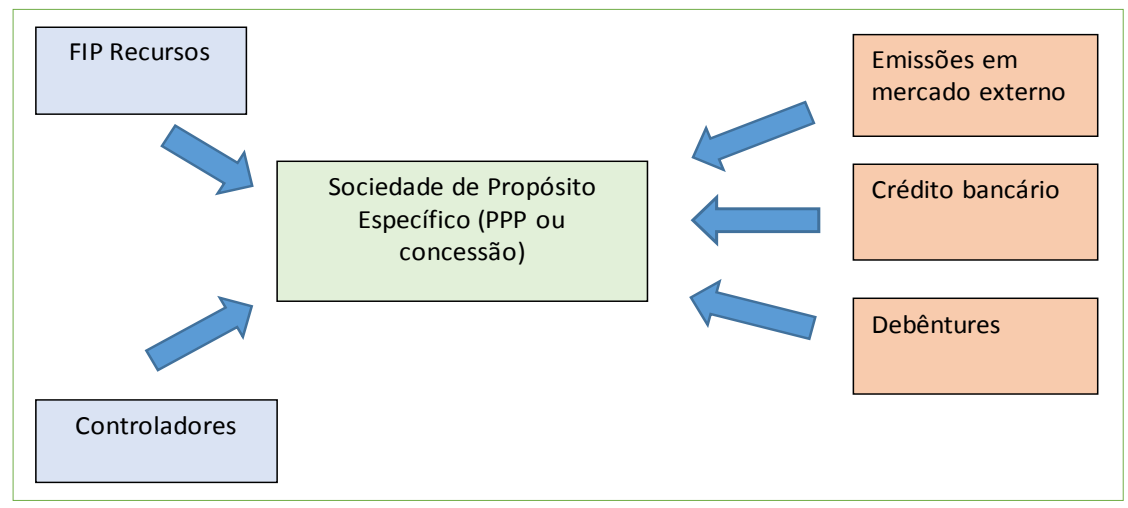

Fonte: Elaboração própria.

Vale notar que uma estratégia de fundo de participações comporta diferenciação nas condições de rentabilidade e risco entre distintos tipos de aplicadores. Seguindo a nomenclatura comumente usada pelo mercado, as cotas podem ser divididas em:

$\checkmark$ Sênior: caracterizada pela rentabilidade definida e especialmente endereçada a aplicadores que não podem assumir os riscos da renda variável. Aplicações do FI-FGTS são candidatos em potencial para este tipo de aplicação.

$\checkmark$ Júnior: caracterizada pela composição entre rentabilidade definida e variável de acordo com o projeto. Por hipótese, a rentabilidade seria uma ponderação levando em conta $60 \%$ de rentabilidade pré-definida e $40 \%$ calculada pelo desempenho do projeto.

$\checkmark$ Subordinada: toda a rentabilidade é balizada pelo retorno do projeto e o cálculo é posterior ao das cotas sênior e júnior, ensejando lucros expressivos em caso de bom retorno do empreendimento. 
A estrutura de financiamento do FIP necessita de fontes diversificadas de recursos, como mostra a Figura 3. A venda de cotas no mercado internacional depende de uma boa formatação de governança, mas é uma possibilidade concreta. $\mathrm{Na}$ forma de cota subordinada, a atratividade deste papel é grande, dada a elevada rentabilidade e o conjunto de garantias sobre as quais as operações de PPP têm se dado.

Os Fundos Soberanos, os fundos de pensão e os grandes fundos de investimento são os objetivos essenciais desta vertente da capitalização do FIP. Ademais, a oferta de uma aplicação do tipo FIP pode melhorar a qualidade dos fluxos de capital no que toca ao seu envolvimento com a economia real. $\mathrm{O}$ diferencial entre a taxa de juros no Brasil e as praticadas nos mercados internacionais tem reforçado a entrada de capitais para participação acionária mesmo em empresas que não operam em Bolsa. O FIP seria uma alternativa interessante para estes aplicadores.

Figura 3

FIP: estrutura de financiamento

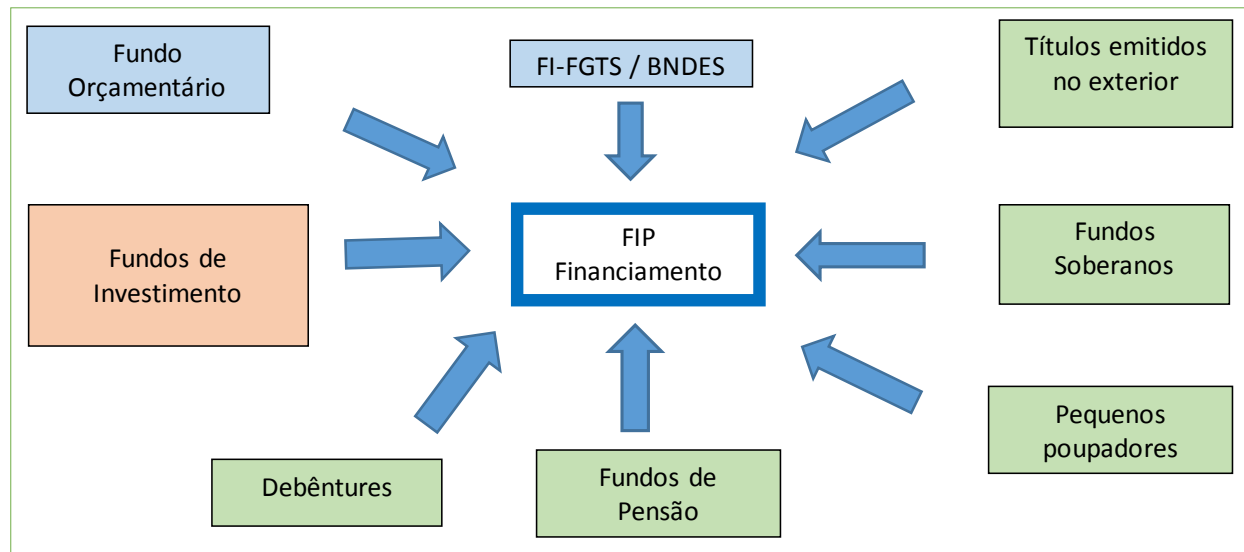

Fonte: Elaboração própria.

É notória a expansão dos fluxos externos que buscam aplicações na economia brasileira. Para investidores estrangeiros, assumir posições em papeis de um fundo como o FIP é mais atrativo do que uma ampla gama de operações com papeis privados ou de empresas públicas, sujeitas ao arbítrio da política econômica em sua formação de $\operatorname{preços}^{16}$. No caso das aplicações em NTN longas ou NTN-F, muito procuradas por investidores internacionais, não cabe dúvida de que a aplicação em cotas de FIP seria um concorrente de peso. Vale lembrar que há alternativas tributárias que poderiam alavancar enormemente o FIP, se a ele fossem estendidos

(16) Uma alternativa operacional, dentre outras, é a utilização de cotas negociadas na Bovespa Fix. É um mercado criado pela Bolsa de Valores de São Paulo para a negociação de títulos de dívida corporativa, ou seja, instrumentos de renda fixa brasileiros que não tenham sido emitidos pelo Governo. 
privilégios concedidos a títulos de emissão privada como as letras imobiliárias ou as debentures de infraestrutura.

Para o mercado financeiro brasileiro vinculado ao financiamento do investimento o formato do FIP tem grandes chances de atrair recursos dos bancos oficiais. Tanto Caixa Econômica Federal quanto Banco do Brasil têm se envolvido cada vez mais com o financiamento ao investimento público. E isso tem se dado em piores condições, formatos menos transparentes e inseguros. O caso do FI-FGTS é emblemático e sua aderência é completa à proposta aqui colocada. $\mathrm{O}$ mesmo pode se dizer do BNDES e do BNDESPAR, para os quais novo modelo seria uma forma institucionalmente muito mais qualificada que a que vem sendo utilizada. Vale frisar que a proposta em pauta é muito superior da ótica da governança financeira e da efetividade das políticas públicas, ao processo recente de expansão do crédito realizado pelas instituições oficiais, com o suporte financeiro do Tesouro Nacional.

Na direção da busca de poupadores de média e pequena dimensão, não há dúvida de que é viável ao FIP lutar por espaços nos mercados de fundos de investimentos de renda fixa e mesmo no campo dos depósitos de poupança. Logicamente, isto só poderia ocorrer com parcerias com instituições privadas de varejo, como Itaú, Bradesco, e os bancos oficiais, para disponibilização das aplicações no FIP em condições operacionais competitivas. As condições de rentabilidade seriam o menor problema a enfrentar, dado o baixo retorno das aplicações acessíveis aos poupadores de pequeno e médio porte.

É forçoso reconhecer que alguns avanços foram feitos. O mais importante foi a criação da debênture de infraestrutura, que possibilita às empresas envolvidas nas concessões e PPP a emissão de títulos mais longos, dotados de benefícios fiscais ${ }^{17}$.

Mas é necessário ir além. O Estado tem responsabilidade primordial na organização dos fluxos de poupança. Há anos, os fundos de investimento recolhem poupanças de indivíduos e empresas, mantendo em seus ativos, basicamente, títulos da dívida pública, grande parte de curto prazo. Se os fundos de investimento aplicassem $1 \%$ de seu ativo no FIP estaria gerado um estoque de recursos de cerca de $0,5 \%$ do PIB.

Os ganhos com a nova institucionalidade seriam diversos. $\mathrm{O}$ principal deles seria a mudança de natureza do financiamento para as ações do Estado: trocando o endividamento genérico pelo financiamento vinculado a projetos. Outro grande ganho seria relativo ao desenvolvimento do mercado de capitais. Ele ganharia com o amadurecimento de novos instrumentos de captação de recursos e reforço de sua institucionalidade. A posição de suporte ao processo dos bancos oficiais não seria

(17) Lei 12.431 de 24 de junho de 2011. 
prejudicada, mas suas responsabilidades ganhariam parceiros de diferentes tipos e portes.

Por fim, para os projetos, os ganhos seriam imensos. A necessidade de formatação do projeto em bases de avaliação econômica de investimentos, custos de operação e retornos econômicos, geralmente não é realizada em investimentos públicos. Já nos períodos de construção e operação, o monitoramento de sua efetiva realização, pelos agentes financiadores, é uma garantia para a sociedade.

\section{3 $O$ investimento e as contas públicas}

A nova forma institucional aqui proposta, ao lado dos aspectos operacionais do financiamento, visa ordenar de forma mais racional a questão da política fiscal. Em diversas ocasiões, o Brasil procurou deduzir os financiamentos relativos ao investimento da mensuração das NFSP. As diversas formas usadas para extração de parcela do investimento dos números do superávit primário envolveram o $\mathrm{PPI}^{18}$, a eliminação das contas da Petrobras e da Eletrobrás e, por fim, o mecanismo de redução de gastos vinculados ao Programa de Aceleração do Crescimento (PAC). Em todos os casos, a ideia, correta em seus termos gerais, é de que, no médio e longo prazos, o crédito investido em projetos com retorno positivo irá gerar os recursos necessários para pagamento do serviço da dívida contratada.

No caso das empresas estatais, a aceitação foi bastante razoável, salvo mais recentemente, devido aos problemas enfrentados pelas duas holdings. No campo orçamentário, no entanto, o mercado financeiro e os analistas econômicos nunca deixaram de olhar para os números do resultado primário sem as deduções derivadas do investimento. De fato, a redução valeu do ponto de vista da legislação e dos números oficiais, mas pouco contribuiu do ponto de vista das expectativas dos agentes econômicos.

Os projetos e recursos públicos envolvidos nas operações financiadas pelo FIP não seriam considerados como gastos públicos, em decorrência de seu retorno financeiro positivo. As pré-condições para a credibilidade dos projetos na nova institucionalidade seriam a transparência e a avaliação de retorno pelo mercado financeiro. Cada projeto teria seu financiamento parcialmente provido pelo FIP após as estruturações financeiras contarem com a participação do mercado de capitais e de instituições financeiras, além da ampla divulgação dos elementos de projeto técnico e de viabilidade econômica.

É crucial alterar a lógica decisória sobre a retirada dos volumes de financiamento do investimento das contas fiscais consideradas para medir o

(18) O Projeto Piloto de Investimento foi proposto em 2005, pela Secretaria do Tesouro Nacional e, a partir de uma aferição de taxa de retorno positiva, propunha fazer a redução do endividamento necessário para o empreendimento dos gastos públicos, na aferição do resultado das contas públicas. 
resultado primário. Ao invés de uma decisão legislativa ou realizada no seio governamental, a segregação do endividamento com possibilidades concretas de retorno seria feita por indicações do mercado. Apenas os projetos com avaliações chancelas pelo mercado privado deixam de ser contabilizados nos resultados fiscais, para efeito de monitoramento da política fiscal. Em caso de fracasso e inviabilização das condições pactuadas no lançamento do projeto, os recursos retornam a ser tratados como gasto normais, à semelhança às demais despesas públicas, voltando a integrar o resultado primário.

\section{Conclusões}

Uma avaliação das contas públicas brasileiras mostra uma realidade paradoxal. Olhada no longo prazo, não há dúvida de que a política fiscal brasileira é capaz de gerar superávits primários, até mesmo continuamente. No entanto, a forma usada para controlar as contas públicas transforma-se em algo como uma paralisia da intervenção estatal. Esta distorção é particularmente grave para uma economia que sempre teve o Estado como agente essencial de seu dinamismo.

Pior, para além do gasto em si, segmentos onde o Estado tem grande poder como regulador e indutor permanecem restritos em seu desenvolvimento pela ausência de uma regulação estatal compatível com o capitalismo atual.

Os esforços aqui realizados visaram dissolver o paradoxo acima citado. Mas essa dissolução significa construir uma saída que gere credibilidade junto ao mercado e, ao mesmo tempo, inicie a reorganização do padrão de financiamento do Estado. Isso, usando as parcerias com o setor privado, sem esquecer de colocá-las na perspectiva de uma economia de tradicional presença estatal no financiamento do investimento, especialmente no campo da infraestrutura.

A importância da intervenção estatal no desenvolvimento é inegável, assim como o fato de que a economia conserva muitos traços da dinâmica do tipo stateled. Mas é crucial ir além da mera reprodução do passado, que já nem é mais possível. A tarefa é colocar o setor público na perspectiva da construção de estruturas institucionais que propiciem uma nova qualidade na ação pública e redefinam seu papel como motor da dinâmica da economia brasileira.

\section{Bibliografia}

AFONSO, J. R. Keynes, crise e política fiscal. Rio de Janeiro: Saraiva, 2010.

AFONSO, J. R.; BIASOTO, G. Investimento Público no Brasil: propostas para desatar o nó. Novos Estudos Cebrap, São Paulo, n. 77, p. 7-26, 2007.

AFONSO, J. R.; BIASOTO, G. Política fiscal no pós-crise de 2008: a credibilidade perdida. In: NOVAIS, L. F.; CAGNIN, R. F.; BIASOTO, G. A economia brasileira no contexto da crise global, São Paulo: Fundap, 2014, p. 251-280. 
AFONSO, J. R; BIASOTO, G.; AMORIM, E. Managing fiscal space in Brazil. Washington, DC: World Bank, 2005.

ARESTIS, P. Fiscal policy within the "New consensus Macroecomics" framework. In: CRELL, J.; SAWYER, M. Current thinking on fiscal policy. Basingstoke, United Kingdon: Palgrave Macmillan, 2009.

BIASOTO, G. A polêmica sobre o déficit público e a sustentabilidade da política fiscal. In: BIASOTO, G.; PINTO, M. P. A. Política fiscal e desenvolvimento no Brasil. São Paulo: Editora Unicamp, 2006. p. 399-422.

BIASOTO, G.; AFONSO, J. R. Um novo paradigma para o investimento público: parcerias, formas de gestão e ampliação das fontes de financiamento. In: OLIVEIRA, G.; OLIVEIRA FILHO, L. C. Parcerias público privadas: experiências, desafios e propostas. Rio de Janeiro: GEN/LTC, 2013.

DAIN, S.; LESSA, C. Capitalismo associado: algumas referências para o tema estado e desenvolvimento. In: BELluZZO, L. G. M.; COUTINHO, R. Desenvolvimento capitalista no Brasil. São Paulo: Brasiliense, 1982. p. 214 -228.

DRAIBE, S. M. Rumos e metamorfoses. Estado e industrialização no Brasil: 1930/1960. Rio de Janeiro: Paz e Terra, 1985.

FIORI, J. L. Para uma economia política do estado brasileiro. São Paulo: Fundap, 1993. (TDI/IESP, n. 11).

EASTERLY, W.; SERVÉN, L. The limits of stabilization: infrastructure, public deficits and growth in Latin America. Stanford: Stanford University Press, 2003.

IMF. Public-private partnerships. Fiscal affairs Department and the Policy Development and Review Department. Washington: International Monetary Fund, 2004.

IMF. Government finance statistics yearbook. Washington: International Monetary Fund, several years.

JALORETTO, C. Seis décadas de déficit público no Brasil. Brasília: STN, 2009.

KEYNES, J. M. Teoria geral do emprego, do juro e do dinheiro. São Paulo: Abril Cultural, 1996. cap. 22-24.

KEYNES, J. M. Collected works. v. 27: Activities 1940-1946. Shaping the post-war world: employment and commodities. Ed. by D. Mooggridge. [s.n.t], 1980.

KREGEL, J. A. Budget deficits stabilization policy and liquidity preference: Keynes's post-war policy proposals. In: VICARELLI, F. (Ed.). Keynes's relevance today. Basingstoke, United Kingdon: Macmillan, 1985.

LERNER, A. Functional finance and federal debt. Selected economic writings of Abba P. Lerner. New York: The New School, 1983. 
LOPREATO, F. C. Dívida pública: o Limiar das Mudanças? Brasília: Ipea, 2015. (Texto para Discussão, n. 2026).

MINSKY, H. P. Estabilizando uma economia instável. São Paulo: Ed. Novo Século, 1986. Cap. 2, 3 e 4.

MARTINS, L. Estado capitalista e burocracia no Brasil pós 1964. São Paulo: Paz e Terra, 1985.

MAZZUCATO, M. The entrepleneurial state: debunking public vs private sector myths. London: Demos, 2011.

MINSKY, H. P. Uncertainty and the structure of capitalist economies: remarks upon receiving the Veblen-Commons Award. Journal of Economic Issues, v. 30, n. 2, p. 357-368, Jun. 1996.

MOLLO, M. L. R.; LOPES, M. L. M. O debate sobre a redução do déficit fiscal no Brasil: uma crítica pos-keynesiana. Nova Economia, Belo Horizonte, v. 21, n. 1, p. 67-103, jan./abr. 2011.

MUSSI, C. H. F.; SILVA, P. F. Ascensão e queda do estado desenvolvimentista: aspectos da crise fiscal no Brasil. Brasília: [s.n.], 1992.

OLIVEIRA, F. A. A reforma tributária de 1966 e a acumulação de capital no Brasil. Belo Horizonte: Ed. Oficina de Livros, 1991.

OLIVEIRA, F. A. Política econômica, estagnação e crise mundial: Brasil, 19802010. São Paulo: Azougue, 2012.

PAULA, L. F. Financiamento, crescimento econômico e funcionalidade do sistema financeiro: uma abordagem pós-keynesiana. Estudos Econômicos, São Paulo, v. 43, n. 2, p. 363-396, abr./jun. 2013.

TCHERNEVA P. The return of fiscal policy: can the new developments in the new economic consensus be reconciled with the post-Keynesian view? New York: Levy Economics Institute, Jul. 2008. (Working Paper, n. 539).

TORRES, E. T.; MACAHYBA, L. O elo perdido: o mercado de títulos de dívida corporativa no Brasil. São Paulo: IEDI, ITB, 2012.

TERRA, F. H. B.; FERRARI, F.; CONCEIÇÃO, O. A. C. A hipótese minskiana de fragilidade financeira aplicada ao setor Público: uma análise para a economia brasileira. Brasília: STN, 2009.

WRAY, L. R. From the state theory of money to modern money theory: an alternative to economic orthodoxy. New York: Levy Economics Institute, Mar. 2014. (Working Paper, n. 792). 